\title{
US dispute over live AIDS vaccine trials
}

[WASHINGTON] The leaders of a group of 50 volunteers who argue that the time is ripe for human trials of an AIDS vaccine containing live HIV claim that the US National Institutes of Health (NIH) are dragging its feet over support for such work.

But NIH leaders and other leading scientists say that, although the volunteers' goal is laudable, it is premature.

The conflict highlights growing differences between scientists and clinicians about what constitutes ethical, timely AIDS vaccine research. It has been stirred up by the high response to a journal announcement soliciting volunteers for a trial of live attenuated - or weakened - virus vaccine; 39 of those who responded are AIDS physicians.

The leaders of the group heading the volunteer effort, the International Association of Physicians in AIDS Care (IAPAC), met staff of the National Institute of Allergy and Infectious Diseases (NIAID) last week. After the meeting, IAPAC's executive director, Gordon Nary, said NIAID staff had made "very, very helpful" suggestions about what would be required for the group to develop a vaccine protocol that would be approved by the US Food and Drug Administration.
But Nary said there are still "major differences" between the volunteers and government scientists about how much animal work remains to be done before human trials of a vaccine of live attenuated virus can proceed.

"How many more deaths are going to move us to humanize science?" asked Nary, arguing that what was needed was "science in the service of humanity, as opposed to science in the service of science".

IAPAC contends that the results of research with a live attenuated monkey analogue of HIV have been sufficiently positive for live, attenuated vaccine to be tried on a small scale in humans. It plans to present a research protocol, aiming to vaccinate up to 15 volunteers by the year 2000, at a Washington conference in November.

Leading scientists and NIH officials call the group's move premature. NIAID's director, Anthony Fauci, says he admires the "altruism" of the IAPAC volunteers, but argues that they are guilty of "misrepresentation: that we have a vaccine in hand and we're ready to go; all we need is the volunteers".

He says there remain substantive obstacles to human trials, especially concern about safety. These can be alleviated only "by

\section{German minister tipped to head UN body}

[LONDON] Klaus Töpfer, Germany's minister for housing and a former environment minister, is being tipped as a leading candidate to succeed Elizabeth Dowdeswell as head of the United Nations Environment Programme (UNEP).

Töpfer's name has informally attracted broad international support, particularly from the United States, Scandinavia and Germany, which is keen for one of its nationals to head a UN agency. “Töpfer's got a lot more status and experience than the others in the field," says one source at an environment ministry in a European Union member state.

Other names that have been mentioned include Michael Cutajar, head of the UN Climate Convention, and John Gummer, Britain's former environment secretary. But none of the three is likely to be supported by Canada, which sponsors Dowdeswell.

Dowdeswell's contract expires at the end of this year, and a consensus is emerging among member countries that UNEP needs a new face. "There are a lot of fundamental problems with UNEP. It needs someone with fresh ideas and vision who can invigorate the place," the source says.

UNEP's controversial 'turf wars' with its constituent conventions have also damaged its image. Some conventions - such as the Biodiversity Convention (see Nature 389, 5;

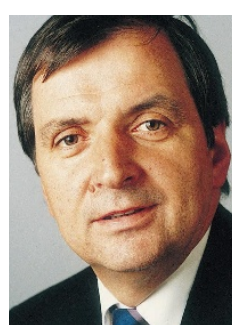

Töpfer: 'has much more status and experience than other candidates' replaced last year. But she was granted a one-year extension by the then UN secretary general, Boutros Boutros Ghali, partly because no candidate had been nominated, and partly because Boutros Ghali was himself about to leave his post, and so was unable to devote time to selecting a candidate.

One reason for a relative lack of enthusiasm for the UNEP post is that it is located in Nairobi. "Had the job been in Geneva, there would have been no shortage of candidates," says one source.

Under United Nations rules, the secretary general takes soundings from member countries before proposing a single candidate who he anticipates will attract widespread support. This name then goes forward for ratification before the general assembly in New York.

Ehsan Masood doing scientific experiments in the orderly scientific fashion that they should be done".

David Baltimore, professor of molecular biology at the Massachusetts Institute of Technology and head of the AIDS vaccine research committee of the NIH, agrees. While calling the volunteers "very brave", he says: "Even if they're willing to put themselves on the line, I don't think that it's appropriate to test materials that we don't feel are reasonably certain to be safe."

Baltimore says that his concern about safety has been increased by at least two unpublished monkey studies that "raise concerns about whether there isn't a fraction of animals who receive the live attenuated virus who go on to develop disease in time".

In justifying its demand for rapid human trials, IAPAC has cited the work of Ronald Desrosiers, a virologist at the Harvard Medical School. Desrosiers has demonstrated immune protection lasting for more than seven years in monkeys vaccinated with live attenuated SIV, the monkey analogue of HIV.

Desrosiers has provided reagents and other starting materials to Therion Biologics of Cambridge, Massachusetts, which is working to develop a live attennuated vaccine. The vaccine was originally developed by Desrosiers and exclusively licensed to Therion.

But Baltimore argues that more urgent than human trials is an understanding of the basic biology of live attenuated virus, without which it is nearly impossible to assess the appropriateness of human trials. He says the NIH's AIDS Vaccine Research Advisory Committee is emphasizing support for basic research in this area, for instance through backing such work in 'innovation grants' announced on Monday (29September).

The fact that live attenuated virus has produced the best results in monkeys means that understanding how it acts needs to be "a very high priority" in government funded research, Baltimore says.

IAPAC solicited volunteers through the August issue of its journal, which goes to 5,500 members in 42 countries. Charles Farthing of IAPAC, medical director of the AIDS Healthcare Foundation in Los Angeles, calls further primate trials "unnecessary, expensive and time-consuming".

Concerns about live attenuated HIV vaccine include the possibility that it might revert to fully virulent form in recipients, and that low-level persistence of the virus might cause AIDS decades after vaccination.

There are also concerns that DNA from the injected virus, which incorporates itself in the host genome, might induce other diseases, for instance by activating cancer-causing genes, and that infants might be harmed by low-level infection induced by vaccination in their mothers. 